\title{
Little knowledgeable mothers of modern world: Diarrhea is an important
}

\section{public health problem}

\author{
Eylem Kuday Kaykısız a,*, Ramazan Güven a, Ali Tongün a, Mihriban Sönmezsoy a \\ a Bitlis State Hospital, Department of Emergency Medicine, TR-13000, Bitlis Turkey
}

\section{ART I C LE IN F O}

\section{Article history:}

Received 08 December 2018

Received in revised form 27 March 2018

Accepted 10 June 2018

\section{Keywords:}

Diarrhea

Under-five children

Mother

Dehidration

Education

\begin{abstract}
A B S T RA C T
As known, diarrheal diseases are both preventable and treatable, is the second leading cause of death among under-five children. Assessing the level of knowledge of mothers about the diarrhea and ORF and increasing the level of community knowledge about diarrhea and ORFs by training the parents in Bitlis city center is among Turkey's less developed eastern provinces. This cross-sectional, descriptive study contucted with a survey. Mothers brought her under-five child to ED with a complaint of diarrhea were included in April-June 2017. 150 mothers included. \%89,3 of these are housewives; \%22,7 were illiterate. $\% 53,3$ of mother have a low; $\% 26,6$ have a medium and $\% 20$ have a good knowledge about diarrhea.ORF usage rates is only $\% 21,3$. Survey scores of mothers who are working out of home, have high education level, are giving prepared or boiled water to her child and are aware from ORF were higher than others. At last, low marriage age of mothers affects level of knowledge about diarrhea. Periodic trainings for mothers have vital proof. Currently the health system-caregivers and the media must act together in an effective fight against diarrheal diseases which are the cause of significant mortality and morbidity. Diarrheal diseases, one of the indicators of development, perhaps the most important preventable causes of child mortality, can only be reduced in this way.
\end{abstract}

(C) 2017. Turkish Journal Park Academic. All rights reserved.

\section{Introduction}

As known, diarrheal diseases which are both preventable and treatable, is the third leading cause of death in all age groups $(\% 6,9)$ and the second leading cause of death among underfive children (1). Worldwide, approximately 1,7 million children suffer from the diarrheal diseases each year and 525.000 under-five children lose their life for this reason (1). In addition to many complications, there is also a burden of economic loss. In the United States, it has been reported an estimated $\$ 6$ billion is lost annually due to diarrhea and its complications (2).

Diarrhea, especially in developing countries, is still a critical issue that threatening public health because of the caregiver'susually mothers- unconsciousness, inadequate hygiene and lack of clean water consumption. In developing countries, it leads to deaths by inducing acute dehydration and fluid electrolyte imbalance due to fluid loss in addition to malnutrition among under-five children. For this reason, oral liquid formulations that are easy to prepare and apply have been developed for dehydration therapy. In addition to being effective and economical, this treatment also prevents to unnecessary intravenous attempts and its complications (3). Oral rehydration fluid(ORF) formulation has been firstly standardized and used in 1975 by World health organization(WHO).

Despite of being a simple, easily accessible and a procedure without complication and WHO's campaigns on this subject, the ORF utilization rate has not yet been increased to above 30 $40 \%(4,5)$. According to the current guidelines of WHO, the basis of diarrhea treatment has been occurred by assessing dehydration to perform proper fluid replacement, maintaining feeding in diarrhea and increasing lactation, zinc 
supplementation and if there is an indication, antibiotic therapy (6).

In year 2009, WHO and UNICEF have launched a global action plan for pneumonia and diarrhea (GAPPD). The aims of this program include to reduce child mortality rate by $1 \%$ and to increase ORF utilization rate to above $90 \%$ worldwide by 2025 (7). In the 21st century, childhood deaths due to diarrhea, which is a preventable and treatable condition, is a health concern. The way in which health costs are diverted to other channels rather than to the treatment of diarrhea and complications is to educate mothers that are generally caregivers.

In our study, it is primarily aimed to assess the level of knowledge of mothers who brought the under-five child with a complaint of diarrhea to emergency department(ED) about the diarrhea definition, etiology, treatment and home care and secondly aimed to increase the level of community knowledge about diarrhea and ORFs by training the parents who participated to study, in Bitlis city center which is among Turkey's less developed eastern provinces.

\section{Material and Method}

\subsection{Study design}

Parents who brought the under-five child with a complaint of diarrhea to ED of a state hospital between April-June 2017, are composed to this cross-sectional, descriptive study's universe. This secondary care hospital is the unique hospital of the city center with a population of 50,000 ; has a capacity of 250 beds, daily number of emergency referral is about 500 patients and 200 of these are consisted of under-eighteen children. It is included mothers have an under-five child (0-48 months) and brought her child with a complaint of diarrhea to ED, volunteer to participate the study and may establish healthy communication (not having language problem, non-mentally disabled). Mothers that may not establish healthy communication, have an unstable child and required urgent intervention, aren't volunteered to participate the study and have a child that older than 5 years were excluded.

\subsection{Data collection}

The data were collected through a face-to-face interview with a survey conducted by one of the authors. Totally, the survey were consisted of 19 questions formed by 9 questions about children including age, sex, number of siblings, status of feeding (breastfeeding, formula milk, supplemental food or only food), specialty of feeding equipment, status of water consumption (tap, prepared or boiled), status of emergency referral for similar complaints, the duration of diarrhea and hospitalization status from diarrhea; 4 questions about mothers characteristics including age of mother, age of marriage, mother's job and maternal education level; 6 questions that evaluating mother's level of knowledge and attitudes about diarrhea including definition of diarrhea, whether it is contagious or not, whether it is required to take a doctor or not, how to change breastfeeding or fluid intake in case of diarrhea, which foods should be given in case of diarrhea, ORF treatment, using and preparing of ORF. A survey scores that measures mother's level of knowledge about approach to diarrhea and dehydration and that the higher scores mean correct answers and the minimum score was 0 and maximum score was 9, was calculated for each participants. When all of the questions measure level of knowledge were close-ended questions as 'yes' or 'no', the question about foods need to be given to child in case of diarrhea was consisted of multiple choice in line with the recommendations of $\mathrm{WHO}$ and was requested to mark one or more choices from the participants. Right foods were accepted as peach, banana, rice, potato and frying foods, acidic drinks and coffee were taken part in wrong foods. Participants have a survey score of 0-4 points were classified as low knowledge of diarrhea (group 1); of 5-6 points were classified as medium knowledge of diarrhea (group 2) and of 7-9 points were classified as good knowledge of diarrhea (group 3).

\subsection{Statistical analysis}

IBM SPSS Statics Version 24 package program was used for statistical analysis of the data. Pearson Chi-Square, Fisher's Exact test and Chi-square trend were used to compare categorical data among the groups; Mann Whitney U for comparison between two groups and Kruskal Wallis $\mathrm{H}$ statistical analysis for comparison between more than two groups were used because of continuous data were not in normal distribution. $\mathrm{P}<0.05$ was considered statistically significant

\subsection{Ethical issues}

Ethics committee of Bitlis Eren University approved the study. The study conducted in accordance with the principles of the Declaration of Helsinki. Before the interview, all volunteers who were able to read and write their name and surnames were invited in writing the informed consent form, declaring that they volunteered to participate in the study. In the case of illiterate participants, the consent form was read by the datacollector to participants and verbal confirmation was obtained.

\section{Results}

\subsection{Study participants}

A total of 150 mothers were included in the study. Average maternal age was $29,19 \pm 5,15(18-40$ ages) and marriage age was $21,67 \pm 3,8(15-32$ ages). $89.3 \%(n=134)$ of participants were housewives and only $10.7 \%(n=16)$ working outside the home. According to mother education levels, $22.7 \%(n=34)$ of participants were illiterate and $42.7 \%(n=64)$ were primary school; $10,7 \%(n=16)$ were secondary school;14.7\%(n=22) were high school and $9.3 \%(n=14)$ were university graduates (Table 1).

When the demographic data of the children of the participants were examined:12\%(n=18) of children between 0-6 months;56\%(n=84) were between 6 months-2 years and $32 \%(n=48)$ were between $2-5$ years. $46.7 \%(n=70)$ of children were male and $53.3 \%(n=80)$ were female. $33.3 \%(n=50)$ of children were the first and only child of the family and $66.7 \%(n=100)$ had 2 or more siblings. $50,7 \%(n=76)$ of the children were fed with breast milk/formula milk+supplemental food; $13,3 \%(n=20)$ were fed only breast milk;6.7\%(n=10) were fed only formula milk; $29.3 \%(n=44)$ were fed only with food. The nutritional equipment of the child was different in $57.3 \%(n=86)$ of children. $61,3 \%(n=92)$ of them consumed tap water while only $13 \%(n=12)$ of them consumed tap water by boiling water and $87 \%(n=80)$ 
consumed without any sanitation process. The remaining $58(38.7 \%)$ children consumed prepared water. It was found that $90.7 \%(n=136)$ of the children had at least one more emergency referral for diarrhea in the last month. $40 \%(n=60)$ of the children were hospitalized due to diarrhea before (Table 1).

\subsection{Factors associated with emergency referral with a complaint of diarrhea}

When evaluating of the association between the demographic data of the parents and the level of knowledge about diarrhea and emergency referral due to diarrhea in the last month, there was a statistically significant difference between the groups in terms of needing a doctor in case of diarrhea, awareness of ORF treatment and status of ORF using $(p<0,05)$. Of the 136 children who had been brought to the emergency service due to diarrhea in the last month, $126(92.7 \%)$ of the mother answered that the diarrheal child needed a doctor when 14 of children who did not have an emergency referral due to diarrhea in the last month, $4(\% 28,5)$ of the children's mother said that the diarrheal child does not need a doctor. All of the 38 mothers (100\%) who had knowledge of the ORF had brought the child to emergency service in the last month due to diarrhea. Of the 112 mothers who were unaware of ORF treatment, $98(87.5 \%)$ had referred to the emergency room with similar complaints within the past month. \%100 of the 32 mothers who used home ORF had at least an emergency referral with similar complaints in the last month and this rate was $88 \%$ among mothers who did not use ORF $(n=118)$.

When the association of demographic characteristics of the children and emergency referral with a complaint of diarrhea in the last month were assessed; $77.7 \%$ of the children aged 0 6 months were brought to the emergency room with similar complaints in the last month, this rate was $90 \%$ in the 6 months- 2 ages group and $95 \%$ in the $2-5$ ages group and this difference reached statistical significance $(p=0,034)$. When evaluated in terms of water consumption, $95 \%(n=76)$ of children using tap water; $\% 93(n=54)$ of children receiving prepared water and $\% 50(n=6)$ of children receiving boiling water were admitted to the hospital with similar

Table 1: Demographics of participants

\section{A. Demographics of children}

\begin{tabular}{|l|l|c|c|}
\hline \multicolumn{2}{|l|}{} & $\begin{array}{c}\text { Numbers } \\
\text { (n) }\end{array}$ & $\begin{array}{c}\text { Rates } \\
\text { (\%) }\end{array}$ \\
\hline \multirow{3}{*}{ Age } & $0-6$ months & 18 & 12 \\
\cline { 2 - 4 } & 6 m-2 ages & 84 & 56 \\
\cline { 2 - 4 } & $2-5$ ages & 48 & 32 \\
\hline \multirow{3}{*}{ Sex } & Male & 70 & 46,7 \\
\cline { 2 - 4 } & Female & 80 & 53,3 \\
\hline Number of & None & 50 & 33,3 \\
\hline
\end{tabular}

\begin{tabular}{|c|c|c|c|}
\hline brothers & 1 or $>1$ broth. & 100 & 66,7 \\
\hline \multirow[t]{4}{*}{$\begin{array}{l}\text { Status of } \\
\text { feeding }\end{array}$} & $\begin{array}{l}\text { Alone } \\
\text { breastfeeding }\end{array}$ & 20 & 13,3 \\
\hline & $\begin{array}{l}\text { Alone formula } \\
\text { milk }\end{array}$ & 10 & 6,7 \\
\hline & Milk+food & 76 & 50,7 \\
\hline & Food & 44 & 29,3 \\
\hline \multirow{2}{*}{$\begin{array}{l}\text { Specialty of } \\
\text { feeding } \\
\text { equipment }\end{array}$} & Yes & 86 & 57,3 \\
\hline & No & 64 & 42,7 \\
\hline \multirow{2}{*}{$\begin{array}{l}\text { Status of water } \\
\text { consumption }\end{array}$} & Tap water & 92 & 61,3 \\
\hline & $\begin{array}{l}\text { Prepared } \\
\text { water }\end{array}$ & 58 & 38,7 \\
\hline \multirow{2}{*}{$\begin{array}{l}\text { Status of } \\
\text { application to } \\
\text { ED with } \\
\text { similarly } \\
\text { complaints }\end{array}$} & Yes & 136 & 90,7 \\
\hline & No & 14 & 9,3 \\
\hline \multirow{2}{*}{$\begin{array}{l}\text { Hospitalization } \\
\text { due to diarrhea }\end{array}$} & Yes & 60 & 40 \\
\hline & No & 90 & 60 \\
\hline
\end{tabular}

\section{B. Demographics of Mothers}

\begin{tabular}{|c|c|c|c|}
\hline \multirow{2}{*}{$\begin{array}{l}\text { Status of } \\
\text { mother's } \\
\text { working out of } \\
\text { home }\end{array}$} & No & 134 & 89,3 \\
\hline & Yes & 16 & 10,7 \\
\hline \multirow{6}{*}{$\begin{array}{l}\text { Maternal } \\
\text { education level }\end{array}$} & İlliterate & 34 & 22,7 \\
\hline & $\begin{array}{l}\text { Primary } \\
\text { school }\end{array}$ & 64 & 42,7 \\
\hline & $\begin{array}{l}\text { Junior high } \\
\text { school }\end{array}$ & 16 & 10,7 \\
\hline & High school & 22 & 14,7 \\
\hline & University & 14 & 9,3 \\
\hline & \multicolumn{2}{|c|}{ Avarage $\pm S D$} & Min.Max. \\
\hline Age of mother & \multicolumn{2}{|c|}{$29,19 \pm 5,15$} & $18-40$ \\
\hline $\begin{array}{l}\text { Age of mother's } \\
\text { marriage }\end{array}$ & \multicolumn{2}{|c|}{$21,67 \pm 3,8$} & $15-32$ \\
\hline
\end{tabular}


complaints in the last month and the diarrhea ratio of children who drink boiled water was statistically significantly lower than the others $(p<0,05)$. There were no statistically significant differences between the groups in terms of other variables $(p>0,05)$.

\subsection{Knowledge of mothers about diarrhea and associated factors of it}

Answers of mothers to survey questions are evaluated; $\% 37,3(n=56)$ of mothers were found not to knew the definition of diarrhea; \%62,7(n=94) were found not to knew whether it is contagious or not; $\% 9,3(n=14)$ were found not to knew that the diarrheal child should take a doctor; $\% 46,7(n=70)$ were found not to knew that she required to increase child's fluid intake in case of diarrhea; $74,7(n=112)$ were found not to knew ORF treatment. İt is concluded that $32(\% 21,3)$ of mothers that are aware from ORF are using these fluids in case of diarrhea and only 18 of these $(\% 11,9)$ were able to achieve preparing the correct ORF. The number of mothers who did not prepare ORF treatment at home was only $6(4 \%)$. When the number of mothers who knew indicated 4 foods required to give in case of diarrhea is $18(12 \%) ; 3$ foods required to give is $20(\% 13,3) ; 2$ foods required to give is $62(\% 41,3)$; only 1 food required to give is $28(\% 18,7)$ and the number of mothers who did not know any food to be given was $22(14.7 \%)$. The response rates of the questionnaires of the subjects are shown in Table 2 (Table 2). $53.3 \%(n=80)$ of the participants were in group $1 ; 26.7 \%(n=40)$ were in group 2 and $20 \%(n=30)$ were in group 3 . The average survey score of the participants was $4.6 \pm 2.28$. Participants' distribution of survey scores was shown in figure 1.

When the factors affecting the survey scores of the parents were examined; there was a statistically significant difference between the groups in terms of whether the mother worked or not, the education level of the mother, the water type consumed by the child and the knowledge of $\mathrm{ORF}(\mathrm{p}<0,05)$. Survey scores of mothers who are working out of home, having a higher education level, taken prepared water to their children and aware of ORF were statistically significantly higher than the others (Table 3, Table 4). There were no statistically significant differences between the groups in terms of other factors such as specialization of feeding equipments, nutritional status and hospitalization status due to diarrhea $(p>0,05)$. According to the Bonferroni corrected Mann Whitney $\mathrm{U}$ analysis to find out which group is the difference in the influence of the learning situation; survey scores of illiterate mothers were statistically significantly lower than primary school, junior high school, high school and university graduates and the survey scores of primary school and junior high school graduate mothers were statistically significantly lower than those of high school and university graduate mothers $(p<0,05)$. The effect of the age of mother and marriage age on the survey score is evaluated and there was a statistically significant difference between the groups in terms of age of mother marriage( $p=0,001)$.In Bonferroni's corrected Mann Whitney $U$ analysis to find out which group the difference is from; the marriage age of group 3 mothers was statistically significantly higher than group 1 mothers $(\mathrm{p}<0,0167)$ (Table 5).

Table 2: The response rates of survey questions by mothers.

\begin{tabular}{|c|c|c|c|}
\hline Questions & & $\begin{array}{c}\text { Numbers } \\
\text { (n) }\end{array}$ & $\begin{array}{c}\text { Rates } \\
(\%)\end{array}$ \\
\hline \multirow{2}{*}{$\begin{array}{l}\text { Diarrhea } \\
\text { definition }\end{array}$} & Known & 94 & 62,7 \\
\hline & Unknown & 56 & 37,3 \\
\hline \multirow{2}{*}{$\begin{array}{c}\text { Contagious of } \\
\text { diarrhea }\end{array}$} & Known & 56 & 37,3 \\
\hline & Unknown & 94 & 62,7 \\
\hline \multirow{2}{*}{$\begin{array}{l}\text { Required to } \\
\text { take a doctor }\end{array}$} & Yes & 136 & 90,7 \\
\hline & No & 14 & 9,3 \\
\hline \multirow{2}{*}{$\begin{array}{l}\text { Status of fluid } \\
\text { intake }\end{array}$} & Reduced & 70 & 46,7 \\
\hline & İncreased & 80 & 53,3 \\
\hline \multirow{5}{*}{$\begin{array}{l}\text { Which foods } \\
\text { should we } \\
\text { give? }\end{array}$} & 0 & 22 & 14,7 \\
\hline & 1 & 28 & 18,7 \\
\hline & 2 & 62 & 41,3 \\
\hline & 3 & 20 & 13,3 \\
\hline & 4 & 18 & 12 \\
\hline \multirow{2}{*}{ ORF definition } & Known & 38 & 25,3 \\
\hline & Unknown & 112 & 74,7 \\
\hline \multirow{2}{*}{ Using of ORF } & Used & 32 & 21,3 \\
\hline & Aren't used & 118 & 78,7 \\
\hline \multirow{2}{*}{$\begin{array}{l}\text { Preparing ORF } \\
\text { correctly }\end{array}$} & Known & 18 & 11,9 \\
\hline & Unknown & 132 & 88,1 \\
\hline \multirow{2}{*}{ Obtaining ORF } & $\begin{array}{c}\text { Prepared at } \\
\text { home }\end{array}$ & 26 & 17,3 \\
\hline & $\begin{array}{c}\text { Taken ORF } \\
\text { package }\end{array}$ & 6 & 4 \\
\hline \multirow{2}{*}{$\begin{array}{c}\text { Correct } \\
\text { preparation } \\
\text { rate } \\
\end{array}$} & Right & 18 & 69,2 \\
\hline & Wrong & 8 & 30,8 \\
\hline \multirow{4}{*}{ Survey scores } & Group 1 & 80 & 53,3 \\
\hline & Group 2 & 40 & 26,7 \\
\hline & Group 3 & 30 & 20,0 \\
\hline & \multicolumn{2}{|c|}{ average $\pm S D$} & Min.-Max. \\
\hline Survey score & \multicolumn{2}{|c|}{$4,6 \pm 2,28$} & $0-9$ \\
\hline
\end{tabular}

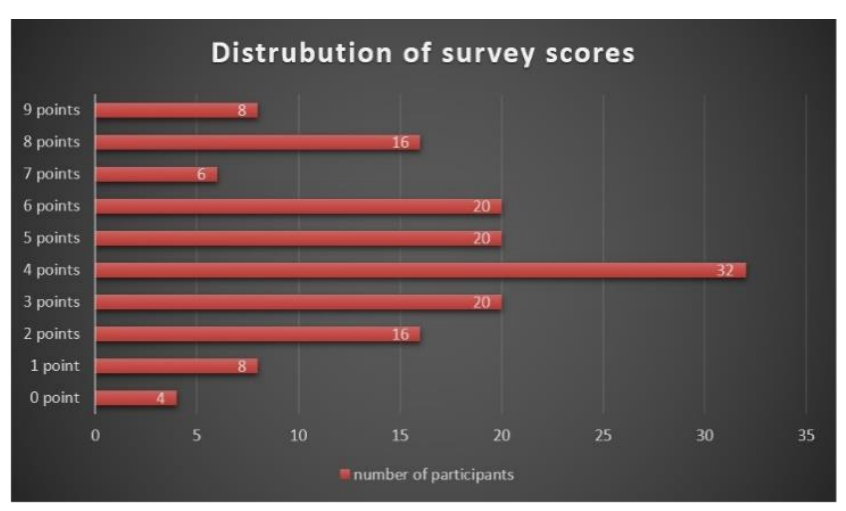

Figure 1. Distribution of survey scores.

\section{Discussion}

In this study,53,3\% of mothers had a low; $26,6 \%$ of them are medium and only $20 \%$ of them have a good level of knowledge about diarrhea and management. Studies supporting this low 
level of knowledge are available in the literature $(8,9)$. In a study, it was reported that only $34 \%$ of mothers were aware of ORF packages and that only $1 / 4$ of the mothers were using them in the case of diarrhea (10). Similarly, in our study, the number of mothers who were aware of ORF treatment was $25.3 \%$ and the usage rate was only $21.3 \%$. Moreover, the result is that the whole does not prepare ORF correctly. In case of diarrhea the care of the housekeeping has not yet been understood by both the health care system and the caregiver. Studies have shown that if training is given, the mothers' behavior in case of diarrhea can be improved $(11,12)$. It has also been previously reported that those who previously received health benefits from diarrhea have more knowledge of ORF. In the same study, it was concluded that the level of knowledge of the mothers who were informed by the media through ORF was higher than the knowledge obtained from a physician or relative (13).Taken into account the low level of knowledge results of our study, both the health system and the media should be reaudited about educating; periodic public education or home visits should be aimed at increasing the level of knowledge of mothers and public spots should be included in televisions which are the most frequently used for communication tool. The incidence of diarrhea is still high because of several factors such as malnutrition (14), low socioeconomically status (15) and maternal education level $(16,17)$, lack of clean water $(18)$, inadequate sanitation and poor hygiene (19), crowded home experience (20) and low maternal age (21) in low and middle income countries (22)

Table 3. Distribution of survey scores of mothers according to status of maternal job, mother's education and water consumption.

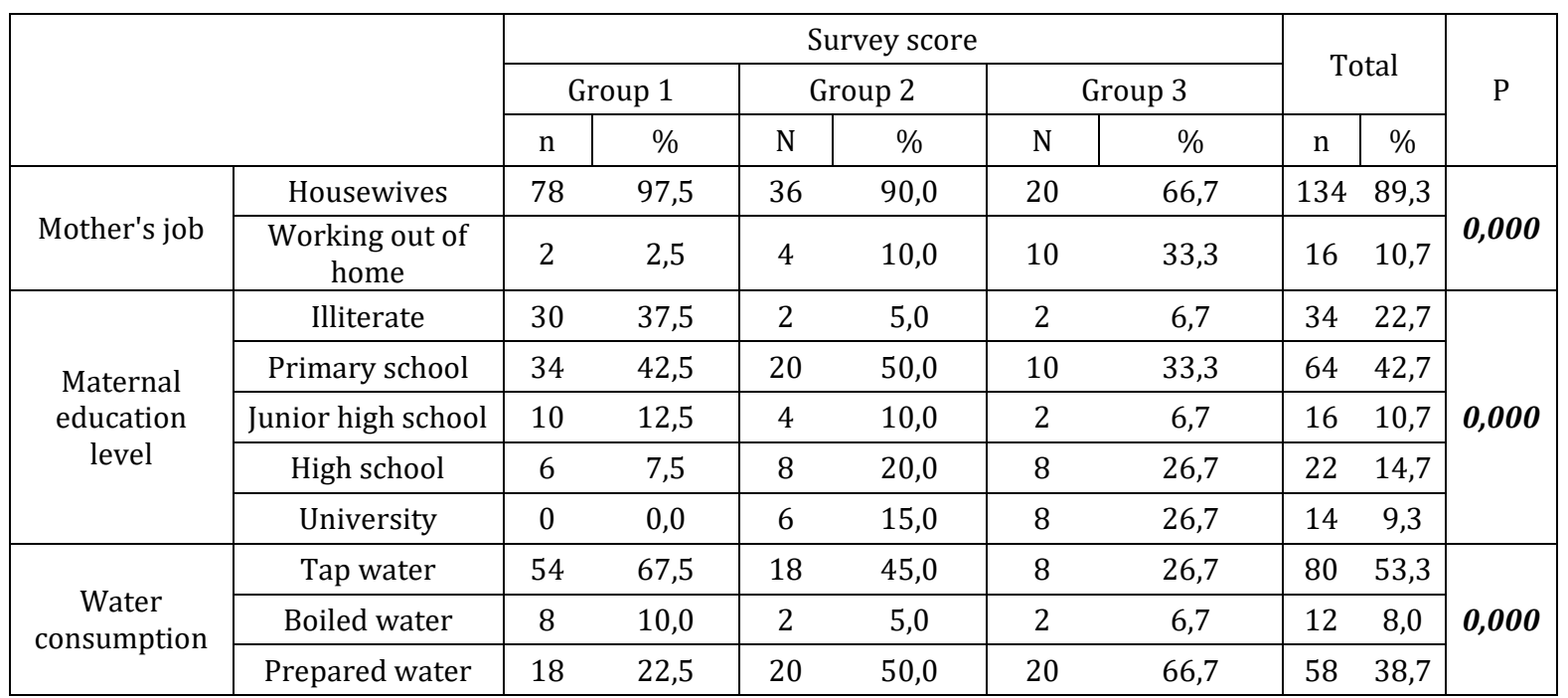

The incidence of diarrhea is higher in the first 2 years of life, with the child growing less (23). The conclusion that the incidence of diarrhea in children aged 6 months to 2 years in our study is higher than in older age groups is consistent with previous studies $(24,25)$. It is not surprising that diarrhea is seen more often because it is a period when children are introduced to diet with supplementary food, usually with cutoffs breastfeeding. According to the results of our work already, $50 \%$ of the participating children with milk+supplemental foods and nearly $30 \%$ were fed only with food. Motarjemi et al was concluded that the contaminant food and waters given in milk cutting period accounted for $70 \%$ of diarrhea attacks in their study (26). In addition, children who received only breast feeding in the first 6 months may have less diarrhea is attributed to not to give additional nutritional support and the proactive effect of breast milk. Antibodies against bacterial strains that cause diarrhea in mother's milk are passed on to baby so that babies may have less diarrheal diseases.

Diouf et al concluded that being mother before than 25-yearold reduces the diarrhea incidence in their study. In addition, in the same study, it was reached that the prevalence of diarrhea can be reduced by being a mother of 40 years and over, having been hygiene education before and doing sanitation like boiling (25). In our study, the level of knowledge about diarrhea was not statistically significant according to the age of the mother. One of the reasons is that your greatest mother is already 40 years old. However, this result can be attributed to having a child in the first year after marriage in the region where the study is conducted and having an average marriage age of $22.14 \pm 6.4$, which is below 25 years of age. The fact that child brides and child-age-bearers are children is a bleeding wound in the whole world, especially in developing countries. Child mothers taking care of a child cause both bereaving the mother's right to live her childhood and leads to incomplete growth of child in many subjects depending on mother's ignorance and immaturity. In our study, the age of being a mother falls to 16 years and the level of knowledge about diarrhea of child brides is significantly lower than adults. Among other factors reported to reduce the prevalence of diarrhea, maternal education level is also important. Studies have shown that the maternal knowledge level of diarrhea is strongly associated with the child's diarrhea status and had a good knowledge mothers' children are less experienced diarrheal diseases (27). Masagnwi et al found that the rate of mother who knew diarrhea was $84 \%$ and reported that an increase in maternal education level and advanced maternal age was associated with a greater awareness of diarrhea definition and symptoms (28).Similar to our study, as maternal 
education increases, the prevalence of diarrhea decreases depending on the elongation of breastfeeding duration, attention to hygiene requirements and better learning of diarrhea prevention measures such as hand washing, attention to clean water consumption $(29,30)$.

Our study is consisted with these results and in accordance with the guidelines of WHO about water quality; supports that boiling water before consumption greatly contributes to fight against diarrhea.

Table 4. Average distribution of survey scores according to status of maternal job and ORF using.

\begin{tabular}{|l|l|c|c|c|}
\hline \multicolumn{2}{|c|}{} & \multicolumn{2}{|c|}{ Survey score } & \multirow{2}{*}{ P } \\
\cline { 3 - 4 } \multicolumn{2}{|c|}{} & average \pm SS & Min.-Max. & \\
\hline \multirow{3}{*}{$\begin{array}{l}\text { Mother's } \\
\text { job }\end{array}$} & Housewives & $4,31 \pm 2,11$ & $0-8$ & \multirow{2}{*}{$\mathbf{0 , 0 0 1}$} \\
\cline { 2 - 4 } & $\begin{array}{l}\text { Working } \\
\text { out of home }\end{array}$ & $7,00 \pm 2,31$ & $3-9$ & \\
\hline \multirow{4}{*}{$\begin{array}{l}\text { Maternal } \\
\text { education } \\
\text { level }\end{array}$} & $\begin{array}{l}\text { Illiterate } \\
\text { Primary } \\
\text { school }\end{array}$ & $3,00 \pm 1,74$ & $1-8$ & \\
\cline { 2 - 4 } & $\begin{array}{l}\text { Junior high } \\
\text { school }\end{array}$ & $3,88 \pm 2,39$ & $0-8$ & \multirow{2}{*}{$\mathbf{0 , 0 0 1}$} \\
\cline { 2 - 4 } & High school & $5,82 \pm 1,89$ & $3-9$ & \\
\cline { 2 - 4 } & University & $7,14 \pm 1,79$ & $5-9$ & \\
\hline \multirow{2}{*}{$\begin{array}{l}\text { Status of } \\
\text { using ORF }\end{array}$} & Yes & $6,56 \pm 1,76$ & $3-9$ & \multirow{2}{*}{$\mathbf{0 , 0 0 1}$} \\
\cline { 2 - 4 } & No & $4,07 \pm 2,12$ & $0-9$ & \\
\hline
\end{tabular}

One of the most important parts of hygiene education is the training of getting clean water, Researchers indicate that even if the water source is clean, there is a high risk of contamination due to storage conditions. The most commonly used sanitation method is boiling (31). There are also publications in the literature that support the belief that diarrhea prevalence can be significantly reduced $(25,32,33)$.

In an Indian study, a child with diarrhea was lacking in taking the doctor and the delay of the healthcare attempt was the result of mortality, which would be a major problem; Interestingly, there was a statistically significant gender bias in delaying delivery to health care in the same study, with less experience in boys (34). Inversely, in our study, it was seen that the participant supported the necessity of reaching the health service for the child who had diarrhea more than $90 \%$, and there was no gender difference in this matter. There is also evidence in the literature consistent with our study that gender has not caused delay in treatment. $(25,35)$.

Table 5: Mean values of maternal age and marital age according to mother's survey group.

\begin{tabular}{|c|c|c|c|c|}
\hline & Groups & Average \pm SD & Min.-Max. & P \\
\hline \multirow{2}{*}{$\begin{array}{c}\text { Age of } \\
\text { mother }\end{array}$} & Group 1 & $29,39 \pm 5,72$ & $19-40$ & \\
\cline { 2 - 4 } & Group 2 & $29,53 \pm 5,32$ & $18-39$ & \multirow{2}{*}{0,353} \\
\cline { 2 - 4 } & Group 3 & $28,2 \pm 2,78$ & $23-34$ & \\
\hline \multirow{2}{*}{$\begin{array}{c}\text { Age of } \\
\text { marriage }\end{array}$} & Group 1 & $20,63 \pm 3,52$ & $15-32$ & \multirow{2}{*}{$\mathbf{0 , 0 0 1}$} \\
\cline { 2 - 5 } & Group 2 & $22,63 \pm 4,22$ & $16-30$ & \\
\cline { 2 - 4 } & Group 3 & $23,17 \pm 3,18$ & $16-30$ & \\
\hline
\end{tabular}

\section{Conclusion}

Although diarrhea is seen as an outdated disease, it is still an important problem, especially in developing countries. The key role in diarrheal diseases is the mothers that are caregivers. Therefore, the poor knowledge level of the mothers will directly affect the health care system. Periodic trainings for mother and other caregivers have vital proof. Unfortunately, health centers are inadequate for these trainings. Currently the health system-caregiver and the media must act together in an effective fight against diarrheal diseases which are the cause of significant mortality and morbidity especially under-five children. Diarrheal diseases that is one of the indicators of development, perhaps the most important preventable causes of child mortality, can only be reduced in this way.

\section{Acknowledgements}

Authors would like to thank the respondents in the study. Our acknowledgement extends to the Bitlis State Hospital's staff to the support of the execution of the study. Authors declare no competing interests. EKK conceived the study and design the trial, supervised the conduct of the trial, data collection and drafted the manuscript, undertook recruitment of participating patients and managed the data, including quality control. RG undertook recruitment of participating patients and managed the data, including quality control MS undertook recruitment of participating patients and managed the data and AT data collection and drafted the manuscript and all authors contributed substantially to its revision.

\section{References}

[1] Lauren, S., Blum, Prisca, A., Oria, Christine, K., Olson, Robert, F., Breiman, Pavani, K., 2011. RAM. Examining the use of oral rehydration salts and other oral rehydration therapy for childhood diarrhea in kenya. Am. J. Trop. Med. Hyg., 85(6),pp.1126-1133.

[2] Guerrant, R.L., Gilder, T.V., Steiner, T.S., et al. 2011. Practice guidelines for the management of infectious diarrhea. Clin Infect Dis; 32: 331-351.

[3] Taşar, M.A., 2003. Ağızdan sıvı tedavisi. Klinik Pediatri, 2:52-58.

[4] Ram, P.K., et al. 2008. Declines in case management of diarrhoea among children less than five years old. Bulletin of the World Health Organization, 86:161-240. .

[5] Forsberg, B.C., et al., 2007. Diarrhoea case management in low- and middle-income countries-an unfinished agenda. Bulletin of the World Health Organization, 85:42-8.

[6] http://www.who.int/mediacentre/factsheets/fs330/en/index. html

[7] Walker, C.L., Rudan, I., Liu, L., Nair, H., Theodoratou, E., Bhutta, Z.A., O'Brien, K.L., Campbell, H., Black, R.E., 2013. Global burden of childhood pneumonia and diarrhoea. Lancet. 381(9875),1405-16.

[8] Othero, D.M., Orago, A.S., Groenewegen, T., Kaseje, D.O., Otengah, P.A., 2008. Home management of diarrhea among underfives in a rural community in Kenya: household perceptions and practices. East Afr J Public Health. 5(3):142-6.

[9] Shah, M.S., Ahmad, A., Khalique, N., Afzal, S., Ansari, M.A., Khan, Z., 2012. Homebased management of acute diarrhoeal disease in an urban slum of Aligarh, India. J Infect Dev Ctries. 6(2):137-42. 
[10] Shah, D., Choudhury, P., Gupta, P. et al. 2012. Promoting appropriate management of diarrhea: a systematic review of literature for advocacy and action: UNICEFPHFI series on newborn and child health, India. Indian Pediatr. 49(8):627-49.

[11] Haroun, H.M., Mahfouz, M.S., El Mukhtar, M., Salah, A., 2010. Assessment of the effect of health education on mothers in Al Maki area, Gezira state, to improve homecare for children under five with diarrhea. J Family Community Med. 17(3):141-6.

[12] Pahwa, S., Kumar, G.T., Toteja, G.S., 2010. Performance of a communitybased health and nutrition-education intervention in the management of diarrhoea in a slum of Delhi, India. J Health Popul Nutr. 28(6):553-9.

[13] Mengistie, B., Berhane, Y., Worku, A., 2012. Predictors of Oral Rehydration Therapy use among under-five children with diarrhea in Eastern Ethiopia: a community based case control study. BMC Public Health. 12(1):1029.

[14] Boschi-Pinto, C., Lanata, C.F., Black, R.E:, 2009. 'The global burden of childhood Diarrhoea'. In Maternal and Child Health: global challenges, programs, and policies. Edited by Ehiri JE; New York: Springer.

[15] Guerrant, R.L., Schorling, J.B., McAuliffe, J.F., de Souza, M.A., 1992 Diarrhea as a cause and an effect of malnutrition: diarrhea prevents catch-up growth and malnutrition increases diarrhea frequency and duration. Am J Trop Med Hyg, 47(1 Pt 2):28-35. .

[16] Hatt, L.E., Waters, H.R., 2006. Determinants of child morbidity in Latin America: a pooled analysis of interactions between parental education and economic status. Soc Sci Med, 62(2):375-386. .

[17] Boadi, K., Kuitunen, M., 2005. Childhood diarrheal morbidity in the accra metropolitan area, ghana: socio-economic, environmental and behavioral risk determinants. J World Health Popul: 2-13..

[18] WHO/UNICEF: Global water supply and sanitation assessment. Geneva: WHO/ UNICEF;2000.Available at: http://www.who.int/water_sanitation_health/

monitoring/jmp2000.pdf (accessed June 1, 2012). .

[19] Makoni, F.S., Ndamba, J., Mbati, P.A., Manase, G., 2004. Impact of waste disposal on health of a poor urban community in Zimbambwe. East Afr Med J, 81(8):422-426. .

[20] Rahman, M., Rahaman, M.M., Wojtyniak, B., Aziz, K.M., 1985. Impact of environmental sanitation and crowding on infant mortality in rural Bangladesh. Lancet, 2(8445):28-31.

[21] Lanata, C.F., Black, R.E., 2008. Diarrheal diseases. In Nutrition and health in developing countries. Secondth edition. Edited by Semba RD, Bloem MW. Totowa, NJ: Humana Press; 139-178.

[22] Fischer Walker, C., Perin, J., Aryee, M., Boschi-Pinto, C., Black, R., 2012. Diarrhea incidence in low- and middle-income countries in 1990 and 2010: a systematic review. BMC Public Health, 12(1):220.
[23] Bilcke, J., Van Damme, P., Van Ranst, M., Hens, N., Aerts, M., Beutels, P., 2009. Estimating the incidence of symptomatic rotavirus infections: a systematic review and meta-analysis. PLoS One 4(6):e6060.

[24] Mannan, S.R., Rahman, M.A., 2011. Exploring the link between food-hygiene practices and diarrhoea among the children of garments worker mothers in dhaka. Anwer Khan Mod Med College J, 1(2):4-11.

[25] Diouf, K., Tabatabai, P., Rudolph, J., Marx, M., 2014. Diarrhoea prevalence in children under five years of age in rural Burundi: an assessment of social and behavioural factors at the household level. Glob Health Action. Dec;7(1):24895. doi: 10.3402/gha.v7.24895.

[26] Motarjemi, Y., Kaferstein, F., Moy, G., Quevedo, F., 1993. Contaminated weaning food: a major risk factor for diarrhoea and associated malnutrition. Bull World Health Organ, 71(1):79-92.

[27] Agustina, R., Shankar, A.V., 2015. Ayuningtyas A et al. Maternal agency influences the prevalence of diarrhea and acute respiratory tract infections among young Indonesian children. Matern Child Health J. May;19(5):1033-46. doi: 10.1007/s10995-014-1603-z.

[28] Masangwi, S.J., Grimason, A.M., 2012. Morse T.D. Pattern of Maternal Knowledge and Its Implications for Diarrhoea Control in Southern Malawi: Multilevel Thresholds of Change Analysis. Int. J. Environ. Res. Public Health, 9, 955-969; doi:10.3390/ijerph9030955.

[29] Yilgwan, C.S., Okolo, S.N., 2012. Prevalence of diarrhea disease and risk factors in Jos University Teaching Hospital, Nigeria. Ann Afr Med. Oct-Dec;11(4):217-21. doi: 10.4103/1596-3519.102852.

[30] Kolahi, A.A., Nabavi, M., Sohrabi, M.R., 2008. Epidemiology of acute diarrheal diseases among children under 5 years of age in Tehran, Iran. Iranian J Clin Infect Dis 3:193-8. .

[31] Institut de Statistiques et d'E'tudes E' conomiques du Burundi (ISTEEBU), Ministe 're de la Sante' Publique et de la Lutte contre le Sida (MSPLS). Enque`te De'mographique et de Sante' Burundi 2010. Bujumbura, Burundi: ISTEEBU, MSPLS, ICF International.

[32] Fewtrell, L., Kaufmann, R.B., Kay, D., Enanoria, W., Haller, L., Colford, J.M. Jr., 2005. Water, sanitation, and hygiene interventions to reduce diarrhoea in less developed countries: a systematic review and meta-analysis. Lancet Infect Dis 5: 4252.

[33] Waddington, H., Snilstveit, B., White, H., Fewtrell, L., 2009. Water, sanitation and hygiene interventions to combat childhood diarrhoea in developing countries. New Delhi: International Initiative for Impact Evaluation.

[34] Malhotra, N., Upadhyay, R.P., 2013. Why are there delays in seeking treatment for childhood diarrhoea in India? Acta Paediatr. Sep;102(9):e413-8. doi: 10.1111/apa.12304. Epub 2013 Jun 21.

[35] Diaz, T., George, A.S., Rao, S.R., et al., 2013. Healthcare seeking for diarrhoea, malaria and pneumonia among children in four poor rural districts in Sierra Leone in the context of free health care: results of a crosssectional survey. BMC Public Health; 13: 157. 